\title{
RAFAEL LASALA Y LOCELA, OBISPO AUXILIAR DE VALENCIA. SU POSTURA ANTE LA EXTINCIÓN DE LOS JESUITAS
}

\author{
Vicente LEÓN NAVARRO
}

\begin{abstract}
Resumen
El presente trabajo expone la figura de Rafael Lasala y su papel como obispo auxiliar de la diócesis de Valencia a la que estuvo vinculado hasta su elección para la de Solsona. Se ofrecen dos visiones de su actuación: la de sus panegiristas y la de sus críticos, merced al poder que tuvo en sus manos y la utilización partidista que hizo de él en la pugna por el control de la enseñanza en Valencia.
\end{abstract}

Muerto el arzobispo A. Mayoral, fue él quien redactó el Dictamen favorable a la extinción de la Compañía de Jesús.

\begin{abstract}
This work presents the figure of Rafael Lasala and his role as assistant bishop of the diocese of Valencia, to which he was linked until he was elected to the one at Solsona. Two views of this conduct are shown here: that of his panegirists and that of his critics, because of the power concentrated on him and because of the partisan usage of this power when fighting for the control of education in Valencia.
\end{abstract}

Once the archbishop A. Mayoral was dead, it was he who wrote the favorable report for the extintion of the Society of Jesus.

Rafael Lasala, obispo auxiliar de Valencia, presentaba su Dictamen acerca de la extinción de la Compañía de Jesús el 21 de noviembre de 1769. No había demorado mucho la petición del secretario de Gracia y Justicia, Manuel de Roda, hecha un mes antes, sobre la conveniencia de esta medida. Su opinión, como no podía ser de otra forma, era totalmente favorable a completar una obra iniciada con la expulsión de los jesuitas años antes, persiguiendo siempre el bien de la Iglesia y del Estado. El episcopado permanecía, de esta forma, ligado a la política regalista de Carlos III frente a la postura reticente, preocupada y atenta de Roma. Unos por sumisión, otros por respeto y algunos por convicción, la mayoría de los prelados opinaron favorablemente sobre 
la extinción de la Compañía de Jesús. Éste es el caso del auxiliar de Valencia. Antes de iniciar el pequeño estudio del Dictamen del obispo Lasala, similar al de la mayoría, creo conviene indicar algunas notas biográficas, que nos permitan conocer, aunque sea sucintamente, los pros y contras del trabajo pastoral de un prelado, cuyo perfil presenta divergencias interpretativas importantes.

\section{NOTAS BIOGRÁFICAS}

Todos los autores coinciden en las fechas importantes relacionadas con la vida de Rafael Lasala ${ }^{1}$; sin embargo, podemos aportar dos puntos de vista bastante distintos, el de sus panegiristas y próximos a su círculo de influencia, que emplean un tono laudatorio, y el de quienes, críticos con su quehacer, miraban con preocupación su poder, minusvalorando e incluso viendo torcidas intenciones en su actitud. Nació en Vinaroz, provincia de Castellón y, a la sazón, diócesis de Tortosa, el 7 de agosto de $1716^{2}$. Hizo sus primeros estudios con su tío fray Máximo Locela, hermano de su madre, en el convento de S. Agustín de Alcira ${ }^{3}$, inclinándose hacia el estado religioso. En efecto, el 23 de agosto de 1731 vestía el hábito agustino en el convento del mismo nombre de Valencia. Allí profesó el 24 de agosto del año siguiente ${ }^{4}$ de la mano del prior fray Tomás Sandoval ${ }^{5}$. Su maestro de novicios sería fray Juan Facundo Meseguer y Niñarola quien ejerció cierta influencia sobre él, hasta el punto que debió ser persuadido para que no le acompañase a tierra de misiones. Para Mollá, uno de sus apologistas, fue «un entendimiento claro y elevado y un ingenio fecundo y sutil, un juicio severo, una memoria vasta y un saber como innato de lo bello, lo fino, lo original, lo sublime, lo sólido y mejor, prometía a Fr. Rafael próspera navegación

1. Algunos autores escriben Lassala; también en documentos de la Curia; (en ocasiones J. B. Hermán) o La Sala (caso de G. Mayans).

2. FUSTER, J., Biblioteca valenciana, Valencia, 1827, p. 134. Cita a sus padres Juan Bautista y Clara. Según fray J. MOLLÁ en Elogio fúnebre del Ilustrísimo señor D. Rafael Lasala, obispo de Solsona, en las exequias que a su buena memoria consagró el real convento de San Agustín de Valencia con asistencia de la M. I. Universidad, Valencia, Hermanos Orga, 1793, fue bautizado el 8 de agosto. BALBÁS, J. A., en Castellonenses ilustres. Apuntes biográficos. Castellón, 1883. Este autor señala la fecha de su bautismo el día 7,pp. 410 y ss. Incurre también en algunas otras inexactitudes.

3. Según Mollá tenía otro tío, Aurelio Locela, en el convento de Agustinos de Valencia. GUITARTE IZQUIERDO, V., Obispos auxiliares en la historia del arzobispado de Valencia, Castellón de la Plana, 1985, pp. 64-66. FELIU, fray D., Oración fúnebre en las exequias solemnes que a influxo de la piedad, amor y celo del llmo. y Remo. Señor D. Fr. Francisco Armañá consagraron a la venerable memoria y eterno descanso del Ilmo. Rvmo. Sr. D. Fr. Rafael Lassala y Locela (27 de julio 1792), Tarragona, Pedro Canals s/a. El P. Feliu proporciona los mismos datos que el P. Mollá.

4. VILLANUEVA, J., Viaje Literario a las Iglesias de España, T. IX, Valencia, imprenta de Oliveros, 1821, p. 83.

5. DEL MORAL, B., «Catálogo de escritores agustinos españoles, portugueses y americanos», La Ciudad de Dios, 67 (1905), pp., 595-96. También MOLLÁ, J., Elogio fúnebre... 
por el océano de la enciclopedia o ciencia universal contra los escollos demasiados frecuentes de la barbarie, la hinchazón, el plagio, el pedantismo» ${ }^{\circ}$.

Estudió filosofía en su real convento de Valencia con fray A. Salanova y, acabado su estudio, le presidió las conclusiones generales con extraordinaria asistencia y aplauso de todas las comunidades. Se graduó en Artes en 1736 y obtuvo el Bachiller de Filosofía y Maestro de Artes en la Ciudad del Turia, aprobando nemine discrepante. Siguió estudiando en el mismo convento el curso de Teología, cumpliendo con las Conclusiones Mensales según costumbre de su religión y defendiendo después quince tratados de teología escolástica en el acto general, según se estilaba entonces. En julio de 1739 le tocaba sostener los tratados de teología expositiva para graduarse de esta materia, logrando el doctorado nemine discrepante. "En esta misma función de Grado defendió la materia de Operibus six dierum según todos los doctores y la especial Sentencia que lleva el P. San Agustín. Hizo luego oposición de lectura que regenta en el dicho convento sin faltarle un voto» y que según fray Feliu fue el 3 de septiembre del mismo año ${ }^{7}$. Señala Mollá que «por desgracia no había llegado aún la gloriosa restauración de las letras y el nuevo alumno, bien que discípulo de un profesor digno (fray A. Salanova) tuvo no obstante que circunscribir sus grandiosos talentos al recinto angosto de una filosofía aristotélica, no ya genuina (...) sino deducida de inexactas traducciones y tortuosos comentarios, aislada y destituida del auxilio de los Matemáticos, aquellas ciencias ilustres, hijas de la demostración y hermanas de la solidez y la evidencia, madres de muchedumbres de conocimientos necesarios a la verdadera física y por extremo útiles a varios menesteres del género humano» ${ }^{8}$. Así, pues, aun no siendo la filosofía de un Gasendo, Descartes, Malebranche, Verulamio o Newton, no era del todo desapacible para quien había de dedicarse al estudio teológico. Es importante constatar cómo Mollá señala la etapa de estudio de Lasala desgraciadamente anterior a la «renovación de las letras» con todos los inconvenientes de unos conocimientos anticuados. Se trata de una época de novedades importante entre la intelectualidad valenciana y de recepción y asimilación de las corrientes europeas, caso de G. Mayans ${ }^{9}$, aunque, en opinión de Florensa, la Universidad no se avino a los cambios que los nuevos conocimientos científicos traían ${ }^{10}$, si bien al margen de la misma se desarrolló una importante actividad, siguiendo las pautas de la Europa ilustrada, a través de libros y autores. Esta situación marca la pugna, que durará mucho tiempo aún, entre el estancamiento y la apertura, entre el pasado y el progreso, entre ciencia y teología, entre razón y fe. Nos importan las palabras de Mollá como exposi-

6. MOLLÁ, J., Elogio fúnebre... Este hombre fue antiguo observante del Convento de nuestra Señora del Socorro y lector del de San Fulgencio. Luego obispo de Filipinas.

7. Archivo de la Universidad de Valencia (AUV), Libro de Méritos, 115, f. 28. FELIU, D., Oración fúnebre...

8. MOLLÁ, J., Oración fúnebre...

9. MESTRE SANCHIS, A., Ilustración y reforma de la Iglesia. Pensamiento político de don Gregorio Mayans y Siscar (1699-1781), Valencia, 1966.

10. FLORENSA, J., «Filosofía, en la Universidad de Valencia (1733-1787), según los opositores a cátedra de Filosofía,, Analecta Calasanctiana, nº 21 (1969), p. 110. 
ción de un proceso de cambio que tendía a dejar un mundo para incorporarse a otro; la escolástica (en su sentido más peyorativo) frente a la revolución científica, aunque de forma tímida.

Oposita en 1740 a la cátedra de filosofía de la Universidad, que ganará al año siguiente $^{11}$. En su primer curso presidió Conclusiones de Súmulas a 22 discípulos y en el siguiente Conclusiones de Lógica y Metafísica a 9. En el último año concurrió a la fundación de Terno con un discípulo suyo y graduó a 4 . Fue también sustituto en la cătedra del Maestro de las Sentencias. Ya en marzo de 1745 obtenía la de Matemáticas con 18 puntos $^{12}$. Así se puede leer, «que en esta su oposición a la cátedra de Visperas de Matemáticas siendo de su obligación sólo, según leyes de la Universidad defender la Astronomía, Cosmografía, Geografía, Astrología y Gnomónica, ha formado sus conclusiones de muchas otras Ciencias Modernas: Geometrí, Machinaria, Óptica, Captóptica, Dióptica, Hidrografia, Centrografia, Architectura Civil y Militar y Tormentaria...» '3. Leyó una hora explicando dos puntos. Uno en los 6 libros de Euclides y otro de Almagesto de Ptolomeo. Siendo catedrático de esta materia luchó por prestigiarla, recordando la memoria de Tosca y Corachán, aunque también reivindicaba algo menos prosaico, el necesario aumento de salarios que hiciese atractiva la ocupación de las cátedras. Del mismo parecer era el otro catedrático, Francisco Ballester. Incluso se planteará la conveniencia del uso del latín o del castellano como idioma vehicular, inclinándose por este último por tres razones: primera, porque así se hacía en otros colegios; segunda, porque posibilitaba el acceso a todo tipo de alumnos (ignorancia del latín) y tercera, por el ejemplo de Tosca ${ }^{14}$. Para Mollá, R. Lasala hubiera sido un Boyle, un Brahe, un Copérnico, un Leibnitz si se hubiera dedicado a la ciencia en vez de a la religión ${ }^{15}$. Destaca, por tanto, su afán por saber, su amor al estudio y su admiración por Luis Vives. Quizás Mollá, citando a hombres protagonistas de la revolución científica estaba marcando el camino a seguir y la necesidad de un cambio de actitud intelectual. Parece indudable que R. Lasala mantiene la línea, aunque a distancia, emprendida por Tosca y Corachán. Su trabajo, pues, se enmarca dentro de un contexto intelectual que facilita su nombramiento como académico de honor y de mé-

11. AUV. Libro de Méritos, 115 , ff. 32 y 33v. Obtuvo 17 puntos de los 22 que concurrieron a la Junta. Según COSTA Y BAFARRULL, D., Memorias de la ciudad de Solsona y de sut iglesia, Barcelona, 1909, p. 501 este mismo año se ordenaba de presbítero.

12. CASTANEDA, V., «La cátedra de Instituciones Teológicas de la Universidad de Valencia y la orden de San Agustín», Revista de Archivos, Bibliotecas y Museos, n 29 (1913), pp. 407-26, alaba la presencia de agustinos en la universidad de Valencia. Cita especialmente a R. Lasala.

13. AUV. Libro de Méritos, 115, f. 134. En 1747 también defendió conclusiones generales en el capítulo provincial de su orden en Barcelona.

14. ALBIÑANA, S., «Francisco Ballester y la enseñanza de las matemáticas en la Universidad de Valencia (1745-1752)», Estudios dedicados a Juan Peset Aleixandre, Valencia, 1982, pp. 65-77.

15. Observemos dos mundos distintos, el de la especulación frente a la ciencia exacta, experimental y la valoración de las cosas útiles y prácticas. 
rito de la Academia de Santa Bárbara ${ }^{16}$ en 1754, y a ocupar diversos cargos dentro de su Orden: rector del colegio de San Fulgencio (había sido elegido en 1752), del convento de Nuestra Señora del Socorro en 1761 y prior del de San Agustín en 1764 (en este mismo año fue elegido vicario provincial de los conventos del Reino ${ }^{17}$ ) y, por segunda vez, en 1767, año (mes de marzo) en que F. X. Vázquez, general de los agustinos, le nombró primer Prefecto General de Estudios del Reino ${ }^{15}$. En esta línea tanto J. Mollá como Jaime Villanueva señalan el encargo que recibió de Manuel de Roda para formar un Plan de Estudios del que parece no ha quedado copia, pero que Mollá asegura haber visto ${ }^{19}$. Por su parte, el arzobispo Mayoral le había nombrado examinador sinodal a finales de mayo de $1761^{20}$. Juan Bautista Hermán, discípulo, amigo y protegido de G. Mayans, llama a Lasala su maestro y habla de su presencia en los tribunales de oposiciones a curatos, aunque en nada le favorece, en su opinión ${ }^{21}$.

Su otro apologista, Vicente Guerau, le señala como un gran predicador, si bien no hemos encontrado las piezas oratorias. Dice: «Él es entre Los filósofos un filósofo enterado de los sistemas antiguos y de los modernos. Entre los teólogos es moralista racional, escolástico sutil, expositivo atenuado, místico exactísimo; a más, se halla. versado en Historia Sagrada, eclesiástica, profana y fabulosa; entre los matemáticos

16. BRECHEZ, J., Arquitectura y academicismo, IVEI. Valencia, 1987. FELIU, D., Oración fúnebre... destaca su valer en el campo religioso reconocido por los agustinos de la Corona de Aragón en el Capítulo celebrado en 1747 en Barcelona. Destaca también su rectorado de San Fulgencio en 1753 y 1759.

17. GUITARTE IZQUIERDO, V., Los obispos auxiliares... Fabián y Fuero en su visita ad limina de 1778 escribía, «El convento grande tiene 77 religiosos. Es casa de estudio y observan en ella las reglas de su instituto. Está bastante dotada de rentas y sus religiosos asistidos de lo que necesitan, pero no guardan vida común perfecta pues perciben limosnas de los sermones que predican y de algunas misas y los maestros tienen distinción en el refectorio.

Conserva en la capital la misma religión el colegio de San Fulgencio, de 21 religiosos cuya principal ocupación es el estudio de la Teología escolástica y Moral. Sus rentas son cortísimas y se valen del arbitrio de tener a pupilaje algunos estudiantes seculares que comen y duermen dentro del mismo colegio. En los demás se gobiernan como el convento grande y lo mismo el de Nuestra Señora del Socorro, extramuros de esta ciudad, también casa de estudio con 35 religiosos (...)», en CÁRCEL ORTí, Ma. M., Relaciones sobre el estado de las diócesis valencianas, Valencia, 1989, vol. 2. p. 1115.

18. ALBIÑNANA, S., Universidad e Ilustración. Valencia en la época de Carlos III. Valencia, 1988, p. 215. Señala que Lasala alentó a Agustín Cabadé a la redacción de Institutiones theologicae in usum fyrorum con planteamientos netamente agustinos. Cfr. Archivo Colegio Corpus Christi, Protocolos, $\mathrm{n}^{\circ}$., 7371 .

19. MASCARÓS Y SEGURA, D., Yndice de los Mss. que el llno. Sr. D. Francisco Pérez Bayer dio a la M. Ylustre Ciudad de Valencia, juntamente con su exquisita Biblioteca para uso de la Universidad Literaria. AUV. Ms. 58 sin foliar contiene Método de estudios para la religión de Agustinos del Obispo Lasala.

20. MOLLA, D., Elogio fínebre...

21. Hermán a Mayans, 4-VI y 23-VI de 1764. Biblioteca Municipal de Valencia (BMV). Serrano Morales, $7268(25)$. 
entiende de todo; lo perteneciente a la arquitectura militar, munitaria y polémica, la tormentaria y la peligrosa arte de la náutica (...). Ama la verdad y aborrece la menti$r a{ }^{22}$. En este mismo sentido se expresa el P. Feliu.

\section{EL OBISPO}

Su nombramiento como obispo auxiliar de Valencia estuvo precedido de otros posibles destinos como las sedes de Orihuela o de Ávila. Finalmente, el Arzobispo Mayoral lo propuso al Rey como coadjutor suyo, siendo nombrado por el monarca el 7 de agosto de 1767, preconizado por el Papa el 14 de diciembre con el título de obispo Adramytium in partibus infidelium y consagrado en San Felipe el Real el 20 de marzo del año siguiente ${ }^{2.3}$ por el arzobispo de Zaragoza, Juan Sáenz de Buruaga y asistido por los prelados José Tormo de Orihuela y José La Plana de Tarazona ${ }^{24}$. Con este motivo se pronunciaron los Discursos gratulatorios de Vicente Guerau y de Luis Adell, éste rector de la Universidad.

No faltan interpretaciones a esta elección, alguna mordaz como la de J. B. Hermán ${ }^{25}$. Pero su ascenso al episcopado se producía en una época difícil. La archidiócesis valentina estaba gobernada por A. Mayoral desde 1736 y su vida se apagaba. La larga permanencia en la sede había tenido sus claroscuros: críticas y alabanzas ${ }^{20}$. De

22. GUERAU, V., Discursos gratulatorios que en las visitas públicas y de ceremonia practicados por la M. N. L. Ciudad de Valencia cerca de los Ilmos. y Rvmos. señores D. José Climent, obispo de Barcelona y Fr. D. Rafael Lasala obispo Adramita con destino de auxiliar de Valencia, en ocasión del ascenso de ambos prelados a sus citados empleos, Valencia, 1768 , imprenta de Benito Monfort.

23. FUSTER, J., Biblioteca...; BALBÁS, J. A., Castellonenses ilustres..., pp. 410 y ss.

24. FERT, R., «De los obispos españoles de las Iglesias in partibus infidelium o auxiliares en las de Españas, en España Sagrada del P. Flórez, T. LI, p. 5. RITZLER, S., Hierarchia Catholica Medii et Recentioris Aevi, Vol. VI, 1730-1799, Patavii, 1957, pp. 62 y 158. Por su parte la Universidad recuerda que cuando un catedrático es nombrado obispo queda vacante la cátedra. Sin embargo el 29 de julio de 1767 se establece que R. Lasala quede con el honor de catedrático de Matemáticas que le corresponde por los más de cinco años de su lectura aunque se provea la cátedra. BMV, Junta de Patronato e 3 , f. 238 y ss.

25. «Estos dos protectores de iliteratos, Chinchilla y Magí, no protegen sino a sus semejantes. Locella va consultado para consejero con dos votos en segundo lugar. Lasala es obispo auxilia»》. Hermán a Mayans, 14-VIII-1767. «El fraile politicón (Magi) ha negociado el auxiliarato para su primo Lassala que será puesto en palacio y tendremos dos obispos y dos provisores $i$ de esta forma no tendrá contrario a Roda i demás anticolegiales. El frailecito triunfante con esta maniobra i esa gente se sostendrá, intellexti?

Si no es que Bayer haga algo como por Lassala de quien me dijo que era honrado i el sardineta pelada Machí (Magí) dicen corrió la estrada por él i para que el auxiliar tuviese más renta». Ibid, 4-9-1767. «Mi catedrático, primo del Mercedario (Magí) i de Locella ya está en el throno. Auxiliar eclesiástico con todas las maniobras Maestrales $i$ auxiliar Mayorálico», Ibid., 15-IX-1767, Serrano Morales, 7268 (25)

26. MESTRE SANCHIS, A., Ilustración y Reforma... También la crítica de J. B. Hermán sobre la actuación y el poder de las camarillas, Serrano Morales, 7268 (24). LEÓN NAVARRO, V.. «Juan Bautista Hermán: discípulo de Gregorio Mayans. Los entresijos de la Curia valenciana. Una persecución en dos actos», en prensa en Saitabi. 
su entorno habían surgido algunos obispos cuyo perfil se adecuaba a las exigencias de los nuevos tiempos: Felipe Bertrán, José Climent, José Tormo y el mismo R. Lasala, agustino y poco afecto, como el resto, a los jesuitas, aspecto éste que hay que resaltar porque a él, muerto A. Mayoral, le corresponderá redactar el Dictamen favorable a la extinción de la Compañía de Jesús. No obstante, el arzobispo ya había dejado el camino expedito a través de sus pastorales sobre el tiranicidio y las falsas ilusiones de las monjas acerca de la vuelta de sus confesores jesuitas, al igual que la mayoría de los prelados españoles ${ }^{27}$. Lasala ejerció como obispo auxiliar hasta la muerte de Mayoral (6-X-1769) ${ }^{28}$ y continuó hasta el nombramiento de Tomás Azpuru (12-III1770) el nuevo arzobispo de Valencia, cuya sede no visitará jamás dado su cargo de embajador de la Corte española ante la Santa Sede, aunque circularán algunas noticias sobre su venida que cuenta J. B. Hermán a G. Mayans en su correspondencia desde Madrid ${ }^{29}$. Pero su ausencia y problemas de salud le llevó a designar a Lasala como Gobernador eclesiástico (10-V-1770) ${ }^{307}$ : "El lo cavildo de 11 de Maig del corresponent any 1770 es resolguè que el Senyor Capitular pasàs a visitar y donar la enhorabuena al IImo. senior bisbe D: Rafael Lasala Auxiliar de aquest Arquebisbat por haberlo nomenat Governador de esta Mitra y en correspondència de haber donat

27. MAYORAL, A., Carta pastoral en que exhorta a sus diocesanos Graduados, Catedráticos y Maestros en Universidades y Estudios que no enseñen la doctrina del Regicidio y Tiranicidio y lo mismo en los Seminarios y los Superiores de las Religiones, Valencia, Palacio Arzobispal, 30 de junio de 1767. Ibid., Carta pastoral a las religiosas de nuestra jurisdicción, a sus directores y demás personas que por vía de consulta las oyen y tratan, Valencia, Palacio Arzobispal, 15 de noviembre de 1767. De su entorno salió también Pedro Albornoz, vicario general y luego obispo de Orihuela (1760-1767). Sobre la tendencia de los prelados a seguir las directrices de los fiscales, especialmente en el caso de la extinción de los jesuitas GIMÉNEZ LÓPEZ, E., «La extirpación de la mala doctrina. Los inicios del proceso de extinción de la Compañía de Jesús (1767-1769)» en Expulsión y exilio de los jesuitas españoles, Enrique Giménez López (De.). Universidad de Alicante, 1997, pp. 229 256. Estudia las relaciones de las monarquías católicas y sus mutuas influencias. Fruto de esto será la postura común frente a la Santa Sede contra los jesuitas y la línea de acción de los Fiscales Generales, resaltando una serie de ideas, tópicos más bien de la literatura antijesuítica al uso y seguida, mayoritariamente por los obispos en sus escritos. DANVILA Y COLLADO, M., Historia de España. reinado de Carlos III, Madrid, El Progreso Editorial, 1894, T. III, señala a Lasala como uno de los obispos favorables a la extinción.

28. PUIG, C., Sermón de las exequias por D. Andrés Mayoral, Arzobispo de Valencia, Valencia, 1769. OLMOS CANALDA, E., Los prelados valentinos, Valencia, 1949, pp. 233-240. MESTRE SANCHIS, A., Ilustración y Reforma..., p. 228, nota 109.

29. Hermán-Mayans, sin fecha, pero debe ser de 1770. Serrano Morales, 7268 (25), carta n., 6791. «Valcárcel me escribe que el nuevo arzobispo viene, con lo que cessará la autoridad del auxiliar $i$, por tanto, discurro que el fraile havrá sentido la dirección i me inclino a que el Rei no le ha queridos.

30. OLAECHEA, R., Las relaciones hispano-romanas en la segunda mitad del XVIII. La Agencia de Preces. Zaragoza, 1965. Según Costa y Bafarrull Lasala presidió en abril de 1770 el Capítulo Provincial celebrado en Valencia, p. 503. No obstante el arzobispo mandó desde Roma rogativas por el venerable Juan Palafox, por su causa, que interesaba al celo del rey y acierto de la Sagrada Congregación. 
raó al Cavildo per medi del Sr. Capitular D. Thomas Azpuru Arquebisbe de Valèncias ${ }^{31}$.

En esta actividad pastoral continuará hasta la muerte del arzobispo (julio de 1772). Cesa entonces en su cargo de Gobernador de la Mitra y el Cabildo le nombra visitador de una parte de la diócesis ${ }^{32}$. En carta a Juan Félix Albinar le dice:

"Por el correo de aier he recivido la noticia de aver fallecido en Roma el 7 del corriente el M.R. Arzobispo de esta diócesis D. Thomás Azpuru por cuia muerte ceso en el gobierno del arzobispado que ejercía en virtud de sus poderes. Y porque como a tal Governador me tenía encargado el Consejo Extraordinario el cumplimiento de las Reales Cédulas y varias órdenes sobre las casas que fueron de los regulares de la Compañía en esta diócesis, hallo de mi obligación manifestar al Consejo por mano de V. S. que hasta el día de aier está hecho en todas las referidas casas quanto pertenecía a mis facultades; y en la que por tres sacerdotes y los sirvientes precisos se halla ocupada interinamente y se continua el culto cumpliendo las dotaciones que tiene; falta formar los estatutos con que debe governarse y no tengo concluidos; porque las funciones de las que existan deven reglarse por el número de individuos que se admitan y éste pende de las rentas que quedarán a la Casa, sobre lo que tiene hecha D. Diego Navarro y Gómez y hasta ver la resolución del Consejo no podian adoptarse los Estatutos. Estos expedientes en el estado que tienen pasaré al nuevo Vicario General que nombre el Cavildo lo que espero se servirá V. S. participar al Consejo para su noticia» ${ }^{33}$.

El siguiente paso será su presentación para la mitra de la diócesis de Solsona (30 de abril de 1772) siendo preconizado por Clemente XIV (15 marzo de 1773).

Apenas si nos quedan noticias de su ejercicio pastoral de esta etapa valenciana, aunque podemos rastrear algunas actividades. Por una parte, el P. Feliu indica que durante cinco años confirió órdenes, presidió concursos de curatos, visitó parte de las iglesias del arzobispado y confirmó 54.000 almas. Por otra, existen algunos documentos escritos en virtud de su actividad episcopal, si bien no excesivamente significativos. Nos referimos a las pastorales y edictos. Por el arzobispo Fabián y Fuero (1774) sabemos que publicó un Edicto de Mayoral en su etapa de Gobernador de la mitra. En él se apremia a los curas a cumplir sus obligaciones y se les insta a que recojan las cédulas del cumplimiento pascual ${ }^{34}$ que, parece ser, dejaba bastante que desear. Se hace eco de las reales órdenes sobre el alistamiento en el ejército $(1770)^{35}$, señalando a los fieles cristianos como ejemplo de buenos vasallos del Rey, del proyecto de reducción de los benefi-

31. Así en el original, excepto la acentuación. ACV, Libro 302, año 1770, f. 82v.

32. FUSTER, J., Biblioteca..., p. 135. MOLLÁ, D., Elogio fúnebre...

33. Archivo del Reino de Valencia (ARV), Clero, legajo 157, $\mathrm{n}^{\circ} .23$, caja 386. Sobre la Casa de los jesuitas y la fundación del Seminario en CÁRCEL ORTÍ, V., «Los orígenes del Seminario Conciliar en Valencia (1767-1793)», Boletin de la Sociedad Castellonense de Cultura, XL (1965). Sobre los planteamientos ideológicos MESTRE SANCHIS, A., «Polémica eclesiológicas en el momento de la fundación del Seminario», Historia del Seminario de Valencia, Valencia, 1991, 9.25.

34. Biblioteca Universidad de Valencia (BUV), Ms. 860 (20).

35. Ibid., Ms., 179 (49). 
cios de la diócesis $(1772)^{36}$, en sintonía con el resto de los obispos, o del control de su clero y asistencia espiritual a las monjas. En julio de 1770 se dirigía a los párrocos, ecónomos, vicarios, etc., sobre la instrucción de los niños, los largos galanteos (noviazgos) de los otorgados y de la indecencia con que se vestían comúnmente los labradores, sin olvidar a las mujeres, recordando que cada una debe vestir según su clase y cuidar mucho las posturas del cuerpo, las miradas, las palabras, los andares y todo cuanto pueda excitar los pensamientos, afectos o deseos impuros. Los curas deben hablar sobre todo esto en sus explicaciones de la doctrina cristiana ${ }^{37}$. Pero, además de las alabanzas surgen las críticas, centradas en las pastorales, que G. Mayans no dudará en comunicar a Campomanes. Se trataba de su postura antimonárquica y fanática por incluir proposiciones que daban a entender a los eclesiásticos que no estaban obligados a obedecer las leyes reales sin la confirmación del ordinario eclesiástico. Grave acusación en tiempos regalistas. Por su parte, Hermán criticaba el contenido, redacción y doctrina ${ }^{38}$.

R. Lasala, por su protagonismo, no podía quedar al margen de los acontecimientos valencianos de la época. Una Valencia que, a través de sus hombres más ilustres, de uno o de otro signo, estaba al tanto de los hechos políticos, religiosos y culturales y vivía una actividad intelectual interesante desde años atrás ${ }^{39}$. Pertenecía al círculo de A. Mayoral ${ }^{40}$, duramente criticado por el erudito de Oliva y su entomo, cuyas posiciones respecto al mundo de la enseñanza, contenidos y métodos, eran conocidas y motivo de enconadas disputas ${ }^{41}$. El arzobispo Mayoral también había mostrado inte-

36. Ibid., Ms., 179 (39). Respecto a este tema se elevó a la Cámara una consulta a la que se contesta el 10 de abril de 1772, BUV, Ms. 908. Ibid., Decreto resolviendo las 10 dudas sobre la reducción de los beneficios de esta diócesis.

37. Ibid., Ms. 179 (40), julio de 1770. J. B. Hermán en carta a G. Mayans se hace eco de esta pastoral, «No escribo como pensaba hasta otro correo al auxiliar en respuesta a su pastoral i sobre si vaca ipso iure mi curato porque me falta tiempo y amanuense», Madrid 10IX-1770, Serrano Morales, 7268 (25)

38. MAYANS Y SISCAR, G. Epistolario XV. Mayans y los altos cuadros de la magistratura y administración borbónica, 2 (1751-1781) Estudio preliminar, transcripción y notas por Antonio Mestre Sanchis y Pablo Pérez Garcia, Publicaciones del Ayuntamiento de Oliva, Valencia, 1997, 4-VIII-1770. Hermán-Mayans, debe ser del año 1770, carta n ${ }^{\circ} 6791$.

39. MESTRE SANCHIS, A., «Reacciones en España ante la expulsión de los jesuitas de Francia», Revista de Historia Moderna. Anales de la Universidad de Alicante, $\mathrm{n}^{\circ} .15$ (1996), pp. 89-116.

40. G. Mayans no mostraba afecto por él, amante del dinero para conseguir lo que quería, «enemigo de los ingenuos i apreciador de los aduladores», G. Mayans-J. B. Hermán, 14X-1769, Biblioteca Archivo Hispano Mayansiano (BAHM), 124.

41. MESTRE SANCHIS, A., Ilustración y Reforma... PESET, M., y J. L., Gregorio Mayans y la reforma universitaria. Idea del nuevo método que se puede practicar en la enseñanza de las Universidades de España, Valencia, 1975. La opinión de Hermán no era muy buena. En carta a G. Mayans le escribe, «...en Valencia apenas se lee ningún libro de sólida erudición. Todo son cosillas, dichos, doctrinas sueltas i francessismos. Ahún aquellos que presumen de filósofos no han lé́do a Cartesio ni a Gassendo i los teólogos ni por el frontispicio a Petavio, Thomasín. Bellos libros hai en aquella ciudad pero ninguno los conoce». 19-VI-1767, Serrano Morales, 7268 (24). 
rés por la educación, favoreciendo, en primer lugar, el establecimiento de los escolapios, que desde su nacimiento habían adoptado la filosofía de Santo Tomás ${ }^{42}$. Era una forma de oposición a los jesuitas (tomismo-antitomismo o, por decirlo mejor, torpe reduccionismo tomismo-antitomismo ${ }^{4,3}$, de control intelectual y de grupo. He ahí, la pugna por los métodos y libros de texto que tanto preocupaba a don Gregorio, tal como se desprende de su correspondencia, de sus obras y del interés por la reforma educativa $^{44}$. Por los escolapios se interesó el Conde de Carlet ${ }^{45}$ pero chocaron con la fuerte oposición de los jesuitas a causa, entre otras cosas, de la enseñanza de la Gramática ${ }^{\text {t6 }}$. A. Mayoral preocupado, pues, por la educación cristiana de los niños, fundó dos establecimientos similares, uno para pobres, al cuidado de los escolapios y otro para nobles, que recibió el nombre de Seminario Andresiano ${ }^{47}$. También F. Fabián y Fuero habla de esta institución de su predecesor en sus visitas ad limina:

«Entre otras cosas de piedad y utilidad está situado dentro de esta capital el colegio de las Escuelas Pías para la Christiana y literaria enseñanza de los niños según el instituto de estos regulares. Se abrió en tiempos de mi digno anterior el ilustrísimo don Andrés Mayoral. En su principio era pequeño, ia por lo reduxido de la fábrica, ia por la falta de maestros y ia por el corto número de oientes, pero después creció marabillosamente porque a la fábrica de esta casa fundada por el mismo arzobispo se añadió el Seminario Andresiano de jóvenes nobles y un templo edificado allí mismo de figura ovalada y hermosa, magnífico y mui adornado, provisto de todo género de alhajas (...).

Habia consagrado el templo el día 14 de abril del año 1773 el obispo actual de la Santa Iglesia de Solsona, entonces auxiliar de Valencia y fue dedicada a Dios en honor de San Joaquín $»^{48}$.

42. DÍAZ, I., «La fïlosofía tomista», Revista Calasancia (1917), pp. 227-247.

43. OLAECHEA, R., «El anticolegialismo del Gobierno de Carlos III», Cuadernos de Investigación. Geografía e Historia, Logroño (1976), pp. 53-90.

44. Por ejemplo, en carta a J. B. Hermán y Mata Linares. Al primero le cuenta cómo se encontró con el obispo auxiliar. Dice que no quería pero tampoco le pesó «porque vino a la conversación mi Gramática (...)», 26-XII-1769, BAHM, 124. Al segundo le habla sobre la promesa que le hizo Mayoral de que los escolapios enseñarían por su Gramática, 17-VII1773, Serrano Morales, 7272 (34).

45. PEÑA, J. J., «Fundación del Colegio de Valencia (1738)», Revista Calasancia (1892), T. IX, pp. 544-553.

46. FAUBEL ZAPATA, V., Acción educativa de las Escuelas Pias en España (1733-1845), Madrid, 1987. LASALDE, C., Historia Literaria y Bibliográfica. Las Escuelas Pías de España, Imprenta A. Amiel, Madrid, 1893, T. I, pp. 160 y ss. El Rey manda que se guarden las normas de fundación sobre la enseñanza de la Gramática, BUV, Ms. 178.

47. CALABUIG Y CARRA, V., La Casa de enseñanza. Fundación del Arzobispo Mayoral. Informe presentado al Excmo. Ayuntamiento. Valencia, Imprenta E. Pascual, 1897. El arzobispo da cuenta de su interés por la educación en sus visitas ad limina de 1761 y 1765 y la fundación del Colegio Andresiano. Ver CÁRCEL ORTÍ, Ma ${ }^{\mathrm{a}}$. M., Relaciones sobre el estado..., T. II.

48. CÁRCEL ORTÍ, Ma. M. Relaciones sobre el estado..., T. II, p. 1118 . Aquí parece confundirse el arzobispo. La consagración tuvo lugar el 18 de abril de 1772. Esta fecha la da Jaime Villanueva en Viaje Literario..., T. IX, pp. 83-84 y Domingo Costa y Bafarrull en Me- 
Las Escuelas Pías, preocupadas por la renovación pedagógica, crecieron gracias a la expulsión de los hijos de san Ignacio hasta el punto, dice Florensa, de ejercer una fuerte influencia en el ámbito educativo y en la introducción de los textos y autores modernos ${ }^{41}$. En 1767 solicitaron a la Ciudad que tomase a su cargo una de las fiestas en honor de san José de Calasanz, estudiante que fuera de la Universidad de Valencia. La Ciudad asumió con agrado este encargo, así como el arzobispado, en atención a la dedicación de los escolapios por la enseñanza pública gratuita ${ }^{51}$. En esta festividad intervino el obispo auxiliar con una Oración Panegírica en honor de este santo al que según 1 . Díaz no dudaron en representarle junto a santo Tomás (todo un símbolo) con soles en el pecho, mirándose el uno al otro ${ }^{51}$. R. Lasala hizo un sermón muy elogioso del santo, como correspondía, resaltando todas las cualidades desde su más tierna infancia y sin ocultar sus dotes taumatúrgicas, más en una línea panegírica que

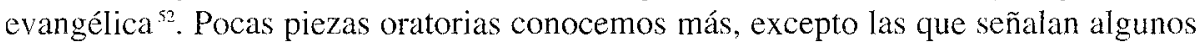
autores como un sermón en el convento de S. Agustín en 1764, según Guerau y el Elogio histórico de san Luis rey de Francia en 1756 en la iglesia de los capuchinos de Alicante ${ }^{53}$.

La expulsión de los jesuitas y el destino de sus bienes, como la Casa Profesa, ocupó y preocupó al obispo auxiliar. Ya en 1767 el arzobispo Mayoral, en carta a Andrés Gómez de la Vega, Intendente Corregidor, le señalaba el posible destino de la iglesia de esta Casa para clérigos seculares, «que sirviendo para su propio bien espiritual aprovecharan a otros», pensando en la congregación del Oratorio del Salvador ${ }^{54}$. En su función de gobernador de la Mitra escribía a Moñino el 22 de noviembre de 1771, «ayer (día 21) se practicó la apertura de la iglesia del Seminario Sacerdotal

morias..., T. II, p. 503 y así lo recoge Vidal Guitarte en Obispos auxiliares..., p. 66. Recordemos que tras la muerte de T. Azpuru, R. Lasala dejaba de ser Gobernador de la Mitra y se elegía un nuevo Vicario General. El 3 de noviembre 1770 había consagrado la iglesia de la orden de Montesa. Siguió los procesos de beatificación ya iniciados de la agustina son María Josefa de Santa Inés y del franciscano A. Margil.

49. HERNÁNDEZ, T. M. «Enseñanza de latinidad y humanidades en la renovación pedagógica del seminario Andresiano de Nobles (1763-1785)» en Estudis, nº 23 (1997), pp. 269 296. Sobre el enfrentamiento jesuitas-escolapios por la enseñanza de la gramática, HERNÁNDEZ, T. M.-LEÓN NAVARRO, V., «La pugna entre jesuitas y escolapios en Valencia por el control de la enseñanza secundaria (1737-1760)», en prensa de próxima aparición en Estuctis, n'. 24.

50. AM V, Libro capitular, 3 de septiembre de 1767, f. 203 y ss.

51. DÍAZ. 1., «La filosofía tomista...»,

52. LASALA Y LOCELA, R., Oración panegírica que en la primera fiesta celebrada en honor de San José de Calasanz, fundador de las Escuelas Pías en su solemne canonización a devoción del llmo. y Rmo. Señor D. Andrés mayoral Arzobispo de Valencia y patrón de su Colegio, Valencia, Benito Monfort, 1768.

53. Ibid., Elogio histórico de San Luis, Rey de Francia. Dijo en su festividad dia 25 de Agosto de 1759 en la Iglesia de los Padres capuchinos de Alicante, Valencia. Benito Monfort, 1759.

54. ARV, Clero, legajo $157, \mathrm{n}^{\circ} .23$, caja 386,8 de diciembre de 1767. 
bajo la invocación de Santo Tomás de Villanueva, a que por Real Cédula se hallaba aplicada la que antes fue de los Regulares llamada la Casa Profesa con la invocación de la venida del Espíritu Santo, habiendo celebrado la primera misa» ${ }^{55}$. Se refería el obispo a la Real Cédula sobre la fundación de Seminarios. La ceremonia se realizó pues el 21 de noviembre, festividad de la Presentación de Nuestra Señora, presidiendo el traslado del Santísimo desde la parroquia de san Pedro Mártir y san Nicolás obispo el propio prelado que ofició la misa de renovación eucarística ${ }^{56}$. En otro escrito, dos días más tarde, le señalaba cómo lo había preparado y organizado todo para que se continuase el culto y se guardase la casa. Y en el momento tuviese el plan y nuevos estatutos los enviaría para su aprobación. Con ello se iniciaba la trayectoria del Seminario de Valencia.

Pero tras los oropeles del episcopado había otros manejos e intrigas en los que R. Lasala participaba. Por una parte, sus enfrentamientos con el Vicario General por la provisión de los curatos ${ }^{57}$; por otra, su postura favorable a alejar a J. B. Hermán de la Corte y su actitud más que dudosa y poco clara en todo este asunto, finalmente, su participación en la dotación de cátedras y canonicatos, muy relacionados con el mundo educativo y en torno al cual giran muchos intereses y se ponen muchas esperanzas, especialmente tras el extrañamiento de los ignacianos. Era el momento oportuno para cambiar planes de estudios y establecer nuevos métodos y orientaciones educativas. Es cierto que había propuestas ambiciosas y muchos intereses creados. Pronto se vio la mano de la intriga y el deseo de controlar un ámbito tan importante; de un lado, el arzobispo y su entorno; de otro, G. Mayans y el suyo, tanto a nivel local como nacional $^{58}$. Pero, además, el grupo valenciano que se movía en la Corte, Pérez Bayer, R. Magí, M. Monfort y otros, jugaba sus propias cartas y establecía sus propios centros de influencia, beneficiando a sus afines ${ }^{59}$. En el fondo, se trataba de una pugna ideo-

55. Ibidem.

56. CÁRCEL ORTÍ, V., «Los orígenes..», p. 225.

57. Mayans escribía a Aranda criticando la actuación de Lasala. MAYANS Y SISCAR. G., Epistolario X. Mayans con Manuel Roda y Conde de Aranda. Transcripción, estudio preliminar y notas por Antonio Mestre Sanchis. Publicaciones del Ayuntamiento de Oliva, Valencia, 1990, pp. 386-87, septiembre de 1770.

58. Mayans a J. B. Hermán. El primero habla con Pedro Mayoral y el Vicario General sobre Hermán, «El obispo La Sala estava con ellos quando yo les bolví la respuesta de Vmd. $i$ dio bien a entender con aquella solapería de gazmoño que su intención es nada favorable $a$ Vmd (...).». 22-I-1768. E1 19 de abril pasaba el obispo por Fuente La Higuera, parroquia de J. B. Hermán a la sazón en Madrid y, en palabras de Mayans, no para cosa buena. Pocos días después (22-IV- 1768) Hermán escribía al de Oliva. No sabe si el Adramita, que se hospedó en su casa, informó bien. La cuestión residía en que la Curia valenciana no quería darse por enterada que el párroco Hermán estaba en Madrid bajo la protección del Conde de Aranda y quieren, contra toda norma jurídica, ponerle un cura ecónomo. De ahî su correspondencia con Lasala, al que tildará de embustero (5-IV-1768), de embustero y artificioso (8-IV-1768). Serrano Morales, 7268 (25).

59. J. B. Hermán-Mayans, «El espíritu escolástico faccionario es el carácter del árabe (Pérez. Bayer) y locellianos clementinos. No ve Vmd. el Hierorche oriolano (Tormo). Crimine ab uno disce omnes. Aquí le conocen por un ignorante...». 24-VI1-1767. Serrano Morales $7268(24)$. 
lógica y de intereses por determinados ámbitos de poder e influencia ${ }^{60}$. En este caso, el control de la enseñanza, que veremos en la elección de planes de estudio, directores y libros, sea en Madrid o en Valencia. De ello sabía algo G. Mayans al ser encargado por Roda para redactar en 1766 un informe sobre la reforma de los estudios. Pero, también intuía los peligros cuando alertaba al Secretario de Gracia y Justicia sobre Pérez Bayer y, especialmente, sobre el obispo auxiliar R. Lasala «hombre embidioso, doloso, fastidioso i que pone todo su saber sobre censurar a los otros» ${ }^{61}$.

Poco después se asistía al primer asalto, teniendo como escenario los Reales Estudios de San Isidro de Madrid, en el que se ponía de manifiesto el poder de los grupos pero, en última instancia, la lucha se dilucidaba entre las más altas instancias nacionales, en opinión de A. Mestre. Se trata de comprobar el poder de Campomanes o de Roda; del Consejo de Castilla o de la Secretaría de Gracia y Justicia; de Mayans y su círculo o de Pérez Bayer y el suyo y, en medio, toda una red de parentescos e influencias de los castellonenses ${ }^{62}$. La elección no recayó sobre Mayans, a quien personalmente no interesaba, ni sobre J. B. Hermán; tampoco sobre R. Lasala, que se quedaría en Valencia por decisión de Roda ${ }^{63}$, pero sí sobre un hombre de Pérez Bayer, Manuel de Villafañe. D. Gregorio temía la elección del obispo auxiliar ${ }^{64}$. Así, pues, la facción bayeriana triunfaba tanto en la imposición del plan de estudios como en la elección del director.

Similar fue el caso del colegio de San Pablo de Valencia. Pérez Bayer colocó a través de A. Gómez de la Vega a Joaquín Segarra de forma provisional. Su gestión fue muy criticada por Mayans y Hermán, entre otros, por el método empleado, por la escasa calidad de los maestros, de los estudios y por el espíritu de facción que reinaba allí. Buen ejemplo de ello sería la depuración del profesor José Plana, quien se atrevió a protestar por el funcionamiento del Colegio y a disentir de los métodos del director para retardar el paso del centro a la jurisdicción universitaria. Culpó a Pérez Bayer, a V. Blasco y a R. Lasala, pero pagó cara su osadía. Según Mayans, en carta a Campomanes, Lasala se hace, cómplice de Segarra y Pérez Bayer frente al Dr. Plana $(s)^{65}$.

60. MESTRE SANCHIS, A., Historia, Fueros y Actitudes políticas. Mayans y la historiografía del XVIII, Valencia, 1970, p. 334. Ibid., «Un grupo de valencianos en la corte de Carlos III», El mundo intelectual de Mayans, Valencia, 1978, pp. 215-240. En correspondencia J. B. Hermán - G. Mayans, Serrano Morales, 7267 (23).

61. MAYANS Y SISCAR, G., Epistolario X..., p. 246, Mayans-Roda 2-VIII-68.

62. Ibid, Epistolario VI. Mayans y Pérez Bayer. Transcripción, notas y estudio preliminar de Antonio Mestre. Valencia, 1977, p. LXIII.

63. MOLLA, J., Elogio fúnebre... DEL MORAL, B., «Catálogo de escritores...».

64. MAYANS Y SISCAR, G., Epistolario VI..., pp. LXVIII-LXIX. Señala A. Mestre que Mayans temía el nombramiento de Lasala para la dirección de los Reales Estudios de San Isidro de Madrid, porque en palabras de Mayans, «Aspiraban estos hijos de la tierra a ser árbitros de la literatura de España y de sus premios, siendo el centro de sus ideas Madrid y Valencia según las oportunidades y acontecimientos». Lasala y J. Segarra estuvieron destinados para ser directores en Madrid y en Valencia respectivamente.

65. Ibid, Epistolario XV..., Mayans-Campomanes, 28-IV-72. 
El otro centro de interés era la Universidad de Valencia. Ya el 17 de octubre de 1769 indicaba J. B. Hermán a G. Mayans que El Chino (Lasala) y Sardineta (Magí) eran enemigos de la Universidad y de su renovación ${ }^{66}$. Aquí radicará la pugna, entre unos y otros, y la pretensión por conseguir la dirección de los estudios. La voz de alarma la daba el mismo J. B. Hermán, «Me ha dicho (Dambila), cosa que yo ignorava, que el Auxiliar pretende la Dirección de essa Universidad y me he alegrado el saver esta especie que concuerda con la que me dijo el Blanco que podía ayudar a su Primo a la instrucción de essa juventud $\gg{ }^{67}$. Alarma o inquietud, Hermán no tarda en ponerlo en conocimiento del Fiscal Campomanes quien, comunica a Mayans, se rió de pensamiento tan ridículo, «con todo le previne que era gente de estraña ambición $i$ directora de Consejos extravagantes, como de otros muchos que le apunté» ${ }^{6}$. Por su parte, D. Gregorio en carta a Martínez Pingarrón resaltaba la ignorancia del Auxiliar. El mismo día hacía lo propio a Hermán, «Es un hombre de perversa intención, con un misterioso silencio sabe ocultar su ignorancia porque pretende la dirección de los Estudios» ${ }^{6}$. En cartas posteriores a su amigo Hermán, el erudito de Oliva seguía pintando la figura del obispo, «Tiene ideas frailescas $i$ no puede ser director con lo que ignora» (24-IV-1770). En la misma dirección se expresaba a Campomanes ${ }^{70}$. El 7 de julio se dirigía a F. Mata Linares, «El obispo Lasala, auxiliar, es hombre a quien han exaltado de las muchas alabanzas de D. Francisco Pérez Bayer y al maestro Magí, para que su facción tenga aquí cabeza i puedan perseguir a los hombres de bien $i$ benemérito, logrando asi el primero el fruto de su ambición $i$ el segundo el de su codicia. Por decirlo en una palabra, este fraile (Lasala) es un zorro sutilissimo vestido de obispo, con pocas letras i muchas mañas i temible por la tendencia de sus calumnias»" Al hilo de esta descripción, Mayans no cesará de manifestar su intranquilidad y la situación, siempre desde su punto de vista, de la Universidad de Valencia, «Creo que estamos en el estado crítico de la perdición o restauración de esta Universidad de Valencia. La facción Pereziana está peleando con el mayor encono para que este obispo auxiliar sea director de los estudios; porque si lo fuere, conseguirá que sea el mantenedor del sistema de la ignorancia; (...) que con ser obispo no ha dejado de ser fraile frailíssimo, con ideas totalmente contrarias a las de nuestro rei...». La opinión de Casamayor iba en la misma línea ${ }^{72}$. Finalmente, Lasala no con-

66. Hermán-Mayans, Serrano Morales, 7268 (25).

67. Ibid., sin fecha, carta $n^{\circ} .6944$.

68. Ibid., sin fecha, carta, $n^{\circ} .6943$.

69. MAYANS Y SISCAR, G., Epistolario IX.., p. 261, 14-IV-1770. Mayans-Hermán, 14-IV1770, BAHM, 124.

70. «Importa que V.S. Ilma. le tenga en este concepto (enemigo de los hombres de bien y sabios) i que le dé a conocer, porque este fraile es intimo de los escolapios, nuevos socios, enemigos de las ciencias $i$ de los sabios, que aqui han tomado un vuelo increíble», 29.V1770, citado por Mestre Sanchis, A. en llustración y Reforma..., 253-254.

71. MAYANS Y SISCAR, G., Epistolario XV..., 7-VII-1770.

72. Ibid., Epistolario X..., p. 387, Mayans-Aranda, 23-X-1770. Hacía alusión a la pastoral denunciada ante Campomanes como antimonárquica. MESTRE SANCHIS, A., Historia, 
seguirá su objetivo, en opinión de J. B. Hermán, por decisión del Rey, aunque él diga que ha renunciado voluntariamente.

La postura de Mayans encaja perfectamente con el alto concepto que tenía de sí mismo, de su trabajo y de la ayuda que podía prestar a la reforma de los estudios universitarios, cuyo espíritu no podía estar contaminado por el de los regulares. Bastante daño, pensaba, habían hecho ya los jesuitas. Así, pues, tras todas estas descalificaciones mostraba también cierto interés por la dirección de los estudios, manifestado directamente a Roda (10-VII-1770) aunque, en cierta forma, no era sino la excusa para llevar a cabo su proyecto reformista y para la implantación de sus libros. Eso sí, con una finalidad clara: la reforma de las letras ${ }^{73}$. Tarea nada fácil tal como se presentaban las cosas y el escaso poder político para su realización. En Valencia Mayans ve con claridad cómo tras la expulsión de los jesuitas, momento ideal para la reforma, el arzobispo y los escolapios se unen aún más en un mismo proyecto educativo en el que no tienen cabida ni los libros, ni el método mayansiano, a pesar de las promesas recibidas en su día, tanto del entorno arzobispal como escolapio, de elegir su Gramática Latina, en la que había puesto muchas esperanzas. Este hecho, estudiado por A. Mestre, frustrará las esperanzas de Mayans de ver implantado su libro y resarcirse así de los gastos de la impresión. Pero sobre todo, será causa para criticar duramente el poder eclesiástico, «alevosía y traición urdida por los escolapios y fomentada por la facción mayorálica y bayeriana unida en este manejo fatal a las letras» ${ }^{74}$. La acusación principal girará en torno a la ignorancia de los frailes, protegida por los Mayorales y sus fieles. De esa misma opinión participan Hermán o Martínez Pingarrón. Para éste los escolapios son «ignorantíssimos y de mala crianza» como corresponde a las huestes frailunas, resaltando la idea de que son continuadores de los jesuitas, compartida por Hermán y Mayans:

"Estimo el librito de la Inutilidad de los jesuitas cuya doctrina es aplicable a la inutilidad de los Escolapios, sucesores legitimos de la gente social y que sin contradicción se van levantando en esta Ciudad, lo qual no tiene remedio si no se procura establecer en la Universidad las cátedras de la buenas letras, prohiviendo a ellos la enseñanza pública. ¿Creerá Vnad. que en el cartel de la puerta del Seminario de San Pablo aun están a la vista de todos la inscripción de que es Seminario de la Compañía de Jesús? Vea Vma. la

Fueros y Actitudes..., p. 334. Dice Casamayor: «Con todo esto yo tengo ya por cierto que essa es la gavilla más fuerte y reunida por los contrarios de Vmd; quiero decir, sus paysanos, reunidos para la exaltación de unas ideas fraylescas y para hacer a Bayer Sthadhouder de la literatura y al (obispo) auxiliar (de Valencia, R. Lasala) el oráculo subalterno y en prueba no quiere Vm. más sino que (Lanz de) Casafonda, cogiendo esotro dáa a Hermán en casa de Bayer le exhortava a que contribuyese a la fomentación de las letras y Universidad. En fin, por este medio y otros de absoluta comprobación, entiendo que Magí afecta uno, Bayer otro y que todos aspiran a hacerse dueños de este reino y valerse de sujetos adictos a sus ideas》, 29-VI-1770.

73. Mayans confiesa a Hermán sus intereses. No le preocupa tanto ser nombrado director de los estudios cuanto que la reforma de los mismos se haga a través de sus libros y método. 3, 6, y 9 de febrero de 1770, en BAHM, 124.

74. Ibid., Epistolario IX..., p. 165, 18-X-1768. 
vigilancia del canónigo Segarra y de los que dicen mandar quitarlo. Así está el descuido con que se enseña en aquel Seminario mucho peor que quando enseñavan los jesuitas, lo qual contribuye mucho a la propagación de los Escolapios» ${ }^{75}$.

Su Gramática no será elegida como libro de texto ni por los escolapios, ni por el colegio de S. Pablo, ni tampoco por la Universidad remisa a aceptar la orden del Consejo. Para Mayans la voz general del obispo auxiliar Lasala y de todos los enemigos que dicen que su Gramática no es para niños, no sirve. En el fondo, existen otros intereses que no tienen en cuenta los buenos libros, el método y la elección de buenos maestros. Se cuestiona, pues, la reforma de las letras y su orientación pública y laica, la manera de entender la ciencia, la historia, la religión, la felicidad pública y el progreso. Los intereses contrapuestos producen enemistades, desengaños y amarguras. En este caso, el obispo Lasala, afín a A. Mayoral y unido a F. Pérez Bayer y R. Magí, favorece a los escolapios frente a Mayans. Las duras descalificaciones de éste son una buena muestra de la profunda enemistad y de la divergencia ideológica. Mirando globalmente, se habla de reformas y reformistas e incluso de ilustrados, pero si analizamos más de cerca a las personas, a sus ideas y actitudes podremos constatar que quizás se hace uso de estos epítetos con mucha magnanimidad e interesada generosidad.

\section{UN DESTINO DEFINITIVO: LA SEDE DE SOLSONA}

Cerramos estas notas con el nombramiento de R. Lasala para el obispado de Solsona. Fue promovido para esta sede el 30 de octubre de $1772^{76}$, preconizado por el Papa el 15 de marzo del siguiente año, tomó posesión el 17 de junio, haciendo la entrada en Solsona el 22 del mismo mes y año ${ }^{77}$. Su trabajo pastoral fue constante y elogiado. Celebró sínodo (1783) en una época en que no se estilaba por problemas político-religiosos. Se adaptó a la lengua de sus fieles: el catalán, con placer, usándolo en sus conversaciones familiares, con los sencillos y en la predicación, recomendándolo también a sus sucesores. Con el fin de hacer más asequible la instrucción catequética escribió dos catecismos, mayor y menor ${ }^{78}$. Cumplió sus visitas ad limina en cuatro ocasiones $(1773,1777,1781,1788)$. Según Mollá fue un obispo digno. Promovió la

75. Mayans-Hermán, 24-IX-1769.

76. Victor de Camba a Mayans: «Creo que han dado el obispado de Solsona a ese señor obispo auxiliar...», 6-XI-1772, Serrano Morales, 7263 (12).

77. FUSTER, J., Biblioteca..., p. 103. RITZLER, S., Hierarchia..., p. 62. En la página 58 señala la renta del obispado. VILLANUEVA, J., Viaje literario..., T. IX, p. 83.

78. MOLLÁ, J., Elogio fúnebre... LASALA Y LOCELA, R., Catecismo Mayor de la doctrina christiana en que se comprehende el menor y se da una instrucción más cumplida de las verdades de nuestra santa religión católica, Cervera, imprenta de la pontificia y real Universidad, 1791. Ibid., Catecismo menor de la doctrina christiana dispuesto por el llmo. Sr. D. Fr... del orden del Gran Padre San Agustín, obispo de Solsona, del Consejo de su Magestad..., Cervera, imprenta de la pontificia y real Universidad, 1791. Señala Mollá que F. Bertrán le escribió para que examinase la traducción del Nuevo Testamento del P. Scío, alabando su sólida instrucción., vasta literatura y gusto (7 de agosto de 1783) Cfr. COSTA Y BAFARRULL, D., Memorias de la ciudad... 
instrucción del pueblo a través de las misiones y del clero con ejercicios espirituales y conferencias morales. Siguiendo las ideas de los obispos «ilustrados» desea ciudadanos cristianos útiles al Estado. Predicó siempre que pudo y se distinguió por su espíritu limosnero y caritativo ante las situaciones críticas, como la epidemia de 1783.

\section{EXTINCIÓN DE LOS JESUITAS. EL DICTAMEN DEL OBISPO LASALA ${ }^{7 \%}$}

A R. Lasala, agustino, favorecedor de los escolapios y antijesuita, le tocó la tarea de redactar el Dictamen a favor de la extinción de la Compañía de Jesús, según la tendencia expresada por el episcopado español para su expulsión unos años antes y siguiendo las arraigadas ideas regalistas de la época ${ }^{80}$.

De acuerdo con la Orden de 22 de octubre de 1769 se dispone a emitir su Dictamen, atendiendo, en su opinión, al fondo de su conciencia, tras haber reflexionado profundamente, dado el carácter grave del asunto, pero también conforme a las «celosas intenciones» del monarca. Se sujeta a sus directrices por completo y reconoce el poder soberano que asiste al Rey para proceder en sus dominios contra cualquier cuerpo (en este caso los jesuitas) que pueda ser nocivo para los intereses de la Nación y de la Iglesia. El obispo no duda en elogiar con largueza el proceder de Carlos III, lleno de luces, de bondad, de piedad, de celo y de religión, guiado e inspirado, en todo momento, por Dios. Las providencias reales son siempre justas y dirigidas al bien común y de la Iglesia. El tono laudatorio no deja lugar a dudas.

Expone, por otra parte, las razones de las críticas antijesuitas desde la fundación de la Compañía. Sin citar a nadie señala los puntos de vista que pronosticaban su ruina. Ya desde el principio de su fundación hubo quienes, con su natural lucidez, vieron los vicios originales y vaticinaron los males futuros. Y, así, se ha demostrado a Io largo del tiempo, por sus consecuencias negativas tanto para la Iglesia como para el Estado. Varios han sido sus desórdenes, contrarios al parecer de los Santos Padres, basados en la apetencia de privilegios, de ambiciones y política mundana, exaltación de sus propios sujetos, aumento de intereses privados y prevalencia de sus opiniones tanto en la cátedra como en el confesionario o en el púlpito. Todo valía para extender su doctrina, sin retractarse jamás de nada.

Los jesuitas, por tanto, «vienen desgraciados desde su origen». La causa principal reside en la soberbia y en el endiosamiento que les hacía especiales e inmunes. Una Sociedad, la de la Compañía de Jesús, no sujeta a nada ni a nadie, que ha procurado el abatimiento de los regulares y hacerse servir de los seculares pero, al mismo tiempo, «sin acción, sin voluntad, sin alma, ni vida para que su General fuese la voz, la alma y acción de todos». La Compañía estaba por encima de todo, anulando individualidades («siervos de la Compañía, no de Dios»); a ella solamente pertenecía el

79. Archivo General de Simanca (AGS) Gracia y Justicia, legajo, 686. Debo el documento a la amabilidad del profesor E. Giménez López.

80. LEÓN NAVARRO, V., «Probabiliorismo frente a probabilismo. Felipe Bertrán: un antijesuita doctrinal» en Disidencias y exilios en la España moderna. Antonio Mestre Sanchis y Enrique Giménez López (eds)., Alicante, 1997, pp. 627-638. 
honor y la fama. Idea expresada por otros muchos obispos en sus respectivos Dictámenes. Para advertir cuán perniciosa sea la Compañía no hay más que reparar en cualquier comunidad de jesuitas y observar su conducta y la oposición sistemática a todo aquello que no participe de sus opiniones. Es decir, cuantos no están con ellos son considerados sus enemigos, «jansenistas», principalmente.

Lasala quiere empezar por los desórdenes y abusos provenientes de la soberbia jesuítica. Algunos de ellos ya los evidenció el prelado Juan de Palafox, víctima de su odio, pero triunfador ahora ${ }^{81}$. Por su parte, los mismos jesuitas se han preocupado de divulgar estos excesos a través de sus escritos, sentimientos e ideas comunes, capaces de perturbar, de un golpe, todo el universo, la Iglesia, el papado o la misma monarquía. Entra el obispo a tratar la política de los ignacianos, no sólo mundana sino también sacrílega, hija de la soberbia, con prevención, sabedor de lo difícil que es sondear este profundo abismo, pero sostiene la idea de la hipocresía jesuítica. En su opinión, han abusado de los más sagrados ejercicios para llevar a cabo sus fines y los compara con epicúreos y estoicos. Con los primeros, por defender que el deleite es el último fin y la suma felicidad del hombre; con los segundos, por considerarlos precursores del pelagianismo y del libre albedrío. Los jesuitas siempre han buscado el signo de la distinción de los demás, no admitiendo otra jurisdicción que la suya propia. Como tenían a menos dedicarse a las tareas pastorales, se empleaban en el ministerio de la confesión, dirección espiritual y predicación e, irónicamente señala Lasala, que para esta tarea todos eran idóneos. Pero es que estos ministerios «les servían grandemente para autorizar el temperamento de su suave doctrina; para disponer las gentes a sus intenciones; para desvanecer quanto estaba contra ellos; para declamar sutilmente contra los que no aprobaban el sistema; para profetizar los desastres que ellos mismos tenían maquinados (...)».

Ha sido a través del confesionario y del voto de obediencia como estos religiosos han ejercido su autoridad, su despotismo. Y, así, han animado su política con el espíritu de ambición y «la ordenaba al sórdido fin de sus propios intereses», so capa de religión. Hipócrita conducta llama a esto Lasala.

No olvida el tema de las misiones, que quieren tener en exclusiva. Éstas son necesarias para la propagación de la fe y todos los eclesiásticos las han realizado cristiana y evangélicamente, menos los jesuitas que se han comportado más como «jefes imperiosos» (mostrando autoridad y despotismo) que como ministros evangélicos, preocupados antes por dominar que por enseñar la verdad:

«Ellos con satisfacción imperiosa mandaban lo que habian de aconsejar, definían lo que habia de probar; y ya desatando matrimonios; ya atándolos a su arbitrio; ya ordenando paces; ya aprobando disensiones; ya cortando pleytos, ya atizándoles; ya sugetando los curas a los pueblos, ya violentando a éstos al interés de los curas; y como si la Religión no fuera otro que politica, y pura institución humana, se hacian dueños de los áni-

81. Una manifestación evidente del antijesuitismo es la postura favorable a Juan de Palafox. El arzobispo de Valencia Tomás Azpuru manda desde Roma rogativas por el Venerable Juan de Palafox, por su causa, que interesa al celo del Rey y acierto de la Sagrada Congregación. Carlos III se había preocupado por esta figura nada más subir al trono de España. 
mos de todos, sometiéndoles a su dominación y autoridad espiritual, haciéndose con esto proclamar tesoreros de la Religión, los que por una tal conducta más bien merecian apedillarse perturbadores de la $\mathrm{Fe}$, de las costumbres y de la piedad».

Por tanto, han buscado su gloria e interés en todos los sitios, no dudando en perseguir a los misioneros de otras órdenes que se cruzaban en su camino, con el único fin de dominar en su propio beneficio.

Todas las devociones y prácticas religiosas conducían a un mismo fin: llevar a los fieles a la Compañía, «de esta suerte, en el mismo acto de hacer devotos a los fieles, les hacian jesuitas». Todo quedaba, pues, reducido a su ámbito (ridículo) jesuítico y acomodado a sus fines. Ponían sus propios libros por encima del Evangelio y simplificaban el camino de la salvación, lisonjeándose de haber hecho más fácil la remisión de las culpas; y cubrían la relajación de las prácticas de su moral con ejercicios de devoción y con la frecuencia de la confesión y comunión. Todo ello resultó muy funesto para la iglesia y para el Estado.

Se pregunta luego el obispo por el ejercicio de la caridad. Si la que practicaban con los demás era similar a la que se tenían entre sí debía ser mala, porque su orden era una fuente de discordias internas, delatándose mutuamente, eso sí, salvando siempre el honor de la Compañía. Su caridad, pues, no nacía del espíritu, sino del afán de singularizarse para mayor gloria de la orden.

No quiere dejar de apuntar sus opiniones sobre la enseñanza. Revela aquí el obispo, aunque inconscientemente, su vinculación con los escolapios. Pone como ejemplo la ciudad de Valencia y resalta, ante todo, que la educación no la ejercen gratuitamente, sino que cobran su salario (en teoría los escolapios no), pero además subraya la mala calidad de ésta, apoyándose en el estado en que encontraron a sus alumnos: «sin crianza, sin instrucción del catecismo y sin rastro de gramática, pero no es de ahora este mal». Los jesuitas, en su opinión, han brillado poco en la enseñanza de los primeros rudimentos, por tanto, nada se pierde con su expulsión y con su extinción. Era notorio que se aplicaron a este escalón educativo solamente en los lugares en que tenían competidores. Éste fue el caso de Valencia cuando se establecieron las Escuelas Pías con modos y métodos distintos ${ }^{82}$.

Ataca, finalmente, el prelado la «igualdad» de la Compañía, que considera imposible en cualquier sociedad humana. De ahí su hipocresía. Más bien parece que la Compañía ha sido un misterio de impiedad y de iniquidad. Esta «igualdad» les convenía para encubrir otros aspectos menos confesables. «Ellos eran soberbios sobre toda soberbia y eran ambiciosos sobre toda ambición». Se resistían a aceptar cualquier imposición, fuera del Papa, de la Iglesia o del monarca. Siempre prontos a defenderse y a atacar a sus enemigos. Se les presenta como versátiles, orgullosos...

Por todo ello conviene su extinción. Es necesario que un cuerpo tan funesto para la Iglesia reciba el último golpe que lo extermine y destruya. Así, desaparecerá su doctrina, el probabilismo, y la cizaña que representa. Con esto se obliga a Roma a extinguir la Compañía.

82. HERNÁNDEZ, T. M.-LEÓN NAVARRO, V., «La pugna entre jesuitas y...». 
R. Lasala se presenta como un obispo consciente de su papel: defiende al monarca y hace buenas sus decisiones, inspiradas por Dios a través de sujetos sabios y celosos. Se muestra antijesuita convencido a través de su profesión agustiniana. Traba bien su Dictamen, aunque no profundiza tanto en las doctrinas cuanto en las ideas más o menos tópicas que circulan sobre los jesuitas. Su análisis no es tan duro y crítico como el de Felipe Bertrán, por ejemplo, aunque coincidente, en líneas generales y visible en algunos puntos:

1.- Señala los abusos, desórdenes y perjuicios que dañan al Estado y a la Iglesia, coincidentes con el obispo de Salamanca, si bien éste insiste más en la perversidad de sus doctrinas.

2.- Se sirven de sus privilegios y utilizan la cátedra, el púlpito, el confesionario y la enseñanza en beneficio propio y de la expansión de sus pésimas doctrinas .

3.- Usan todo en su provecho; mundanizan incluso la religión y se muestran ambiciosos y despóticos, ateos, herejes e idólatras.

4.- Su fin último es la gloria de la Compañía, antes que la de Dios, a la que se inmolan como individuos, incapaces de ejercitar la caridad ni con ellos mismos, ni con los demás.

5.- No son como el resto de religiosos. Ellos son especiales, singulares y no permiten que nadie les controle ni esté por encima. No se someten a ninguna jurisdicción y atacarán a quien intente someterlos, sea el Papa o el Rey. Son versátiles y, sobre todo, soberbios e incapaces de retractarse.

6.- Su moral es tan pésima que incluso de ella se avergonzarían los gentiles.

7. - Finalmente, por todo esto, es necesaria la extinción de los jesuitas, en beneficio de la Iglesia, de la Religión y del Estado.

En resumen, pues, he intentado presentar una breve semblanza de R. Lasala, contrastando los distintos puntos de vista sobre su persona y su quehacer pastoral e intelectual. Faltarían, sin duda, otros documentos, que no he podido consultar, que ampliarían el conocimiento de este agustino en sus diversas facetas pero, la visión que aquí se aporta permite, al menos, comprender la complejidad del personaje y de la época. Su Dictamen, poco original, responde, en líneas generales, al cliché antijesuítico del momento y a las necesidades regalistas de la monarquía, que los obispos asumen, aparentemente, con respeto y devoción. 